\title{
Considerations on Research of Environmental Risk Prevention and Control in "12th Five-Year Plan" Period
}

\author{
Pengli Xue ${ }^{1}$, Xiaofeng Sun ${ }^{1}$, Yun Song ${ }^{1}$, Yanjun Cheng ${ }^{1}$, Dezhi Sun ${ }^{2}$ \\ ${ }^{1}$ Environmental Protection Institute of Light Industry, Beijing, China \\ ${ }^{2}$ Beijing Forestry University, Beijing, China
}

Received 2013

\begin{abstract}
Along with the environmental pollution causes complexity and diversity increases ceaselessly, "national environmental protection" Twelfth Five "planning" (hereinafter referred to as "planning") will be the environmental risk prevention as the "12th Five-Year Plan" one of the important tasks, including advancing environmental risk management in the whole process, key areas the environmental risk prevention measures. The whole process environmental risk management covers a risk source recognition, receptor vulnerability assessment, environmental risk characterization, risk decision and risk assessment of accident loss. This article from the environmental risk source classification, environmental risk classification management, environmental emergency response and environmental risk and insurance environment four aspects put forward the "12th Five-Year Plan" whole process environmental risk management content, to further reduce our country environmental pollution accident risk and policy makers to provide some decision support.
\end{abstract}

Keywords: Whole-process Environmental Risk Assessment and Management; Environmental Risk Source Stage

Division; Environmental Risk Regionalization; Emergency Management; Environment Insurance

\section{Introduction}

In recent years, along with the rapid advance of China's industrialization and urbanization, the density of population and economy increase sharply; meanwhile, the chemical enterprises are gathering towards the major riverside and seaside cities with the convenient transportation and resources, therefore leading to the enormous and sudden environmental risks caused by the improper distribution. The production, storage and transportation of dangerous materials of chemical enterprises are on the rise, which results in the frequent environmental pollution accidents of China. Based on the analysis of the dynamic change in time and space of environmental pollution accidents from 1990 to 2007, Xue (2011) points that China's sudden environmental pollution accidents decrease from 3.462 (1990) to 462 (2007) thanks to the release of a series of management rules on poisonous, harmful and dangerous chemicals, the implementation of evaluation system of safety production and environmental impact, and the issuance of technical guide for environmental risk evaluation of projects, especially the stricter environment supervision of risk enterprises. Seen from the spatial distribution characteristics, China's sudden environmental pollution accidents in the past ten years mainly came from the Yangtze River Delta and Liaodong Peninsula; however, with the implementation of the western development strategy, the exhaustion of eastern environmental capacity and the industrial upgrading, many heavily polluting enterprises begins moving to the west, and the enterprises specialized in paper making, coal chemicals and heavy metals smelting have become the major risk sources of western areas; the environmental risk caused by improper distribution and the soar of regional industrialization and urbanization result in the continuous increase in environmental pollution accident loss of China.

As the cause of environmental pollution is more and more complicated and diversified, the National 12th FiveYear Plan for Environmental Protection (hereinafter called the Plan), for the first time, lists the environmental risk prevention as an important task in the "12th Five-Year Plan" period which is parallel to the total emission reduction and quality control, and makes decisions to promote the whole-process risk management, improve the environmental risk management measures and establish the mechanism of environmental accident damage and compensation.

\section{Risk Source Classification/Gradation Management}

The classification of environmental risk source is the premise for risk identification; after the classification, it is necessary to establish the grading standard system for each kind of environmental risk source to assess the hazard of risk source and further ascertain the grade of 
environmental risk source, and then work out the monitoring and management measures against each grade of environmental risk source, especially the major ones. In this way, the environmental risk can be reduced from the source,

To comprehensively master the spatial distribution and hazard level of the fixed environmental risk sources of China, identify the major risk sources, and provide basic information for the establishment of China's regional environmental risk source files and database, the Ministry of Environmental Protection, in May 2009, carried out the environmental risk and chemicals inspection on the enterprises of 3 national key sectors (petroleum processing and coking, chemical material and product manufacture and medicine manufacturing), totaling 10 industries and 35 sub-industries. In a sense, the enterprises of 35 sub-industries involved in this inspection belongs to the environmental risk sources defined according to the industry characteristics classification, with each enterprise equivalent to one environmental risk source. However, the relevant research by Wei Keji et al. (2010) summarizes the classification of environmental risk source into the followings: the environmental sufferer-based classification, such as the water environment risk source, atmospheric environment risk source and soil environment risk source; the material state-based classification, such as the gaseous environment risk source, liquid environment risk source and solid environment risk source; the transmission route-based classification. Wen Lili et al. (2010) presented the design principle of major environmental risk source monitoring system based on the classification into liquid source, solid source and mobile source.

The environmental risk source gradation management aims to effectively avoid risk of each grade of environment risk of the same category; the risk source gradation management can save the management cost and shorten the emergency response time, therefore enhancing the efficiency of risk management. Wei Keji (2010) built the environment hazard index according to the hazard of risk source to water, atmosphere and soil to divide the risk sources into four grades, and then presented the identification standard system of major environmental risk source according to the said gradation.

Many industries in the various categories of national economy have the environmental risk and it is hard to make the uniform classification and assessment, therefore, the chemical raw materials/products manufacturing industry or the chemical industry park shall be chosen for the initial research on the environmental risk source assessment and gradation management standards, and we shall work out the prevention and early warning measures against the major risk source of such industry in aspect of technology transformation, equipment elimination, personnel training, etc. with a purpose to eliminate the major petrochemical environmental pollution accidents at their early stage.

As to the VOCs pollution risk, source tracing and characteristics of industrial VOCs emissions in China should pay more attention to the production of VOCs, the storage and transport, industrial processes using VOCs as raw materials and use of VOCs-containing products.

\section{Research on Vulnerability of Environmental Risk Targets}

From the point of region, the environmental risk sufferer is a compound system including the social economy, natural ecology and other factors, so the object suffering the sudden environmental pollution accident risk includes the social economy and ecosystem, and the integrated vulnerability of risk sufferer is composed of the vulnerability of social economy and that of ecosystem.

For the social economic system, we mainly consider the scale of regional population and economy, the regional accident prevention and emergency measures, the scale of other infrastructures and so on; for the natural ecosystem, we mainly consider the sensitive ecosystem, including the ecosystem of drinking water source area, natural reserve and wetland.

During the "12th Five-Year Plan" period, we shall research the vulnerability of social environmental risk sufferer through such aspects as population density, the density of hospital and urban lifeline, regional earlywarning capacity, proportion of public education in GDP, number of hospital bed per 10,000 persons, per capita GDP, regional emergency evacuation capacity, sudden environmental pollution accident response capacity and prevention capacity, etc. and figure out the pertinent and practical measures to isolate risks or enhance the risk resistance capacity for the much vulnerable social risk sufferers; the research on vulnerability of natural ecological environmental risk suffer shall be carried out through the sensitivity and adaptability of regional ecosystem (including water area ratio, regional environmental improvement index, river regulation investment ratio, standard discharge rate of industrial wastewater) and related to the regional emergency monitoring and response to effectively reduce the damage caused by the ecosystem pollution accident.

\section{Environmental Risk Zoning Management}

At present, the Emergency Response Law of the People's Republic of China is lack of the relevant implementing rules, there is no adequate legal basis for implementation and the relevant supporting policies are not formulated yet, so there is no pertinent guide on the prevention and management of environment risk. During the "12th FiveYear Plan" period, we shall, based on the classification 
and gradation of environmental risk source, comprehendsively consider the environmental risk sufferer to realize the regionalization for environmental risk in the major industries, such as the petrochemical industry, and regard it as the important basis for the environmental risk zoning management.

The environmental risk regionalization is the basis and prerequisite for the environmental risk zoning management. At present, the method and theoretical system of China's environmental risk regionalization are still in the research phase, and the environmental risk zoning management is not implemented in any specific administrative and regional system yet.

Yang Jie et al. (2006) took the economic zone along Yangtze River in Jiangsu Province as an example wherein a single development zone is regarded as the research unit to analyze the risk source, control mechanism and sufferer, and obtained the comprehensive risk index of each industrial park, which was then made into different grades, and finally they presented the corresponding risk management measures. Peng Wangminzi (2009) analyzed the characteristics of each risk source of a certain petrochemical industrial source in Guangzhou and then assessed the environmental risk though the information diffusion method; on the basis of this, he divided the environmental risk of industrial park into four grades according to the relevant grading standard. Xue Pengli (2011) adopted the top-down and bottom-up method to regionalize the sudden environment risk of Shanghai and got 2 risk regions, 5 risk sub-regions and 21 risk segments; meanwhile she presented accident prevention and early-warning measures for different types of risk areas, realizing the environmental risk zoning management in Shanghai.

In order to further prevent the environmental risk caused by the improper industrial distribution during the "12th Five-Year Plan" period, we shall, based on the environment function zoning, ecological zoning and main function zoning of our country, further consider the environmental risk source, the vulnerability of social environment and ecological environment sufferer in a comprehensive manner to assess the environmental risk and obtain the environmental risk zoning map, and then analyze this map together with the land use plan of China and the overall urban planning map to strengthen the space regulation and provide the objective and visual basis for the adjustment of industrial structure and layout, the reasonable layout and development of industries with high risk of serious pollution and the implementation of risk prevention measures, with a purpose to actually realize the environmental risk zoning management.

Based on the current and future industrial emissions of VOCs in China, the research on the risk zoning for the air pollution can provides scientific results for control the VOCs pollution.

\section{Environmental Risk and Environmental Insurance}

The environmental insurance is an effective green insurance system against the pollution issues which is widely adopted in the world and aims to compensate for the personal injury and properly loss of the third party caused by the environmental pollution in the insured site and assume the expenses incurred in the process of pollution cleanup and elimination; this system can not only help to reduce the environmental disasters and accidents but also alleviate the government's environmental protection burden and guarantee the rights and interests of the environmental pollution victims and their families.

During the "12th Five-Year Plan" period, we shall further establish and improve the laws and regulations system of environmental pollution responsibility insurance and specify the compulsory direction and transitional measures for the establishment of this insurance system. Additionally, the Ministry of Environmental Protection shall work together with the China Insurance Regulatory Commission and insurance companies to develop the reasonable and practical environmental insurance products for the major pollution industries, and establish a three-party interaction mechanism among the government department, insurance company and bank; improve the establishment of some environment insurance product service agencies and the environmental responsibility arbitration agencies; make more efforts to explore the implementation of the compulsory liability insurance in the industries with serious pollution and high environmental risk, make the environmental protecttion department to formulate the catalogue of such Industries (and their products) and relate the environmental pollution responsibility insurance with the credit qualifycation of the enterprises in this catalogue. At the same time, the government shall also provide the necessary policy support for the development of environment pollution responsibility insurance. Set up the compensation funds for environmental pollution damage to pay for the part beyond the insurance in case of major environment pollution accident and pay the emergency disposal expense for any other party. On this basis, during the "12th Five-Year Plan" period, we shall extensively carry out the pilot work in the high accident area and the special region with high environmental risk as much as possible, such as selecting the enterprises in the industry dealing with hazardous chemicals transportation, taking hazardous materials as raw materials and discharging hazardous pollutants or other hazardous wastes in the Yangtze River Delta and Zhujiang River Delta. 


\section{Conclusions}

The frequent sudden environmental pollution events not only caused great loss to the social economy and affected the harmony and stability of society but also vanished the environment governance achievement of many years, with the damage caused to the ecological environment hard to be restored within short time. From the "12th FiveYear Plan" to 2020 is the mid-to-late period of industrialization, which will see the fast development and reformation of China's economy and society, and the stage characteristics determine the importance of environmental risk factors. The environmental risk factors, even reduced in amount and improved in quality, will also exert negative influence to the ecosystem and human health, and there are still some factors of environment safety and environment risk are beyond the control over amount and quality. the National 12th Five-Year Plan for Environmental Protection, for the first time, lists the environmental risk prevention as an important task in the "12th Five-Year Plan" period which is parallel to the total emission reduction and quality control, and make decisions to strengthen the environmental risk prevention and control over the key fields through implementing the wholeprocess management of environmental risk, strengthening the nuclear and radiation safety management, restraining the high-frequency state of heavy metal pollution events, promoting the safe treatment and disposal of solid wastes and improving the chemical-induced environmental risk prevention and control system.

This paper analyzed the classification and gradation of environmental risk source, environmental risk regionalization, environmental pollution emergency response at three levels (enterprise, park and region) and environmental risk \& environmental insurance, and presented the emphases of the whole-process management of environmental risk of China during the "12th Five-Year Plan" period, and provided theimportant basis for the prevention of China's environmental pollution accident and the industrial distribution in the same period.

\section{REFERENCES}

[1] P. L. Xue and W.H. Zeng, "Trends of environmental accidents in China from 1990 to 2007", Frontiers of Environmental Science and Engineering in China, Vol. 5, No. 2, 2011, pp. 66-276. doi:10.1007/s11783-010-0267-1

[2] F. Y. Li, J. Bi, C. S. Qu et al. "Research and Application of Whole-process Environmental Risk Assessment and Management Mode," China Environmental Science, Vol. 30, No. 6, 2010, pp. 858-864.

doi:10.1007/s11426-010-0120-1

[3] K. J. Wei, "Research on Identification of Major Environmental Risk Sources in Nanjing Chemical Industrial Park", Master Thesis of Beijing Forestry University, [D], 2009, pp. 49-52.

[4] L. L. Wen, Y. H. Song, B. F. Yue et al, "Research on Construction of Major Environmental Risk Source Monitoring System", Chinese Perspective on Risk Analysis and Crisis Response, 2010, pp. 154-197.

[5] P. L. Xue, "Research on Sudden Environmental Pollution Accident in Shanghai," Doctoral Theses of Beijing Normal University [D]. Beijing, 2010, pp.151-156.

[6] Q. Jia, "Research on Assessment and Grading Method of Sudden Environmental Risk of Petrochemical Enterprises," Journal of Environmental Sciences, Vol. 30, No. 7, 2011, pp. 1510-1517.

[7] J. Yang, J. Bi, and J. B. Zhou, "Development of Environmental Risk Monitoring and Early-warning System along the Yangtze River in Jiangsu Province," Resource and Environment in the Yangtze Basin, Vol. 15, No. 6, 2006, pp. 745-749.

[8] W. M. Peng and X. F. Shi, "Environmental Risk Regionalization Based on Information Diffusion Method," Environmental Science and Technology, Vol. 32, No. 9, 2006, pp. 191-193.

[9] P. L. Xue and W. H. Zeng, "Shanghai Environmental Pollution Emergency Risk Zoning along the Yangtze River," China Environmental Science, Vol. 31, No. 10, 2011, pp. 1743- 1750. 